\title{
Public Goods: Re-examination, Related Concepts and Distinctions
}

\author{
Jing Chen \\ School of Tourism and Management, Wuhan Business University, Wuhan Hubei China
}

\begin{abstract}
The essay is aiming at answering'How do economists distinguish between public goods and private goods? What problems does the existence of public goods pose for the market? How might the government intervene to address the problems of public goods? Illustrate with an example or examples drawn from your work experience or the academic literature'. This essay consists of three parts exploring different issues related to the resolution of public goods and externalities problems. The first section is to identify the public goods and private goods from an economic scope. Whereas the second part is to explore the possible obstacles the public goods would pose for the market. And the final part is to figure out how government would resolve the addressed problems by intervention and use valid empirical evidence to support the effectiveness of these intervention and actions.
\end{abstract}

\section{Introduction}

The essay is aiming at answering'How do economists distinguish between public goods and private goods? What problems does the existence of public goods pose for the market? How might the government intervene to address the problems of public goods? Illustrate with an example or examples drawn from your work experience or the academic literature'. This essay consists of three parts exploring different issues related to the resolution of public goods and externalities problems. The first section is to identify the public goods and private goods from an economic scope. Whereas the second part is to explore the possible obstacles the public goods would pose for the market. And the final part is to figure out how government would resolve the addressed problems by intervention and use valid empirical evidence to support the effectiveness of these intervention and actions. Much more, to deliberately elaborate the issues the public goods give rise to the market, the government intervention should be taken into account. Thus, market failure focusing on government's actions increases the total level of a public good, but the fact that the public good level is considered typically under-provided. And the consequence that welfare of all households will be improved by increasing the total public good provision through government intervention is just a fairy tale. In reality, after the intervention, some households may end up paying more taxes than the value of their original original contribution, and there is no reason to expect the increase in the public good level will be enough to compensate each and every one of such households. And the situation may somehow result in market failure or so- called government failure. In the sense described above, this paper would discuss several government intervention regarding market failure and provision of public goods to test the effectiveness and validity of government actions. In addition, this paper would also discover possible more practical alternatives and contingency plans to dealing with such problems and failure and provide pragmatic insights for future studies of this related realm.

\section{Disparity between public goods and private goods}

Public goods or services are the ones that cannot be provided by the private sector directly through the market but must be provided by the government or the public sector in a non-market manner [9].

Literally speaking, a public good is a product that can be enjoyed by all members of society, and is noncompetitive and non-exclusive in a strict sense. Noncompetitiveness means that the consumption of a public good by one person does not affect its availability to others, which represents the marginal cost of providing the good to another consumer at a given level of production is zero. Non-exclusivity is that someone consumes a public good in a way that does not exclude others from consuming the good (whether they pay for it or not), or the cost of exclusion is high [4].

A good that is usually not exclusive or (and) competitive, and once produced, cannot exclude some people, is called a (pure) public good. Exclusivity of a good refers to that the producer or purchaser of the good can easily exclude others from obtaining the benefits derived from the good; competitiveness of a good is that 
the quantity of the good consumed is related to the cost of producing that quantity [4].

As a result, a public good, in an economic point of view, can be characterized by three aspects: the first side is, a public good contains indivisibility of utility, it is provided to the whole society and has the characteristics of common benefit or joint consumption. It can be enjoyed jointly by all people in the society, and cannot be divided into several parts and attributed to some individuals, families or enterprises respectively. The second respect is, a public good possesses nonexclusivity of consumption. That is, the enjoyment of a public good by a certain individual, family or enterprise does not affect or prevent others, families or enterprises from enjoying them at the same time. The third filed is, a public good has the unstoppable nature of benefit which means no technical way to exclude individuals, households or enterprises that refuse to pay for a public good from benefiting from it [9]. In this regard, public goods or services are the symmetry of "private goods", and whether the goods contain rivalry and exclusiveness are the critical criteria in differentiating public goods from private ones.

\section{Potential problems arisen from the provision of public goods to the market}

The provision of public goods would give rise to some severe problems, disorder and erratic error within the market.

The major obstacle that public goods would address to the market is disturbing the market order, and leader to market failure. The non-exclusive and noncompetitive nature of public goods consumption makes the consumption and production of public goods possess their own characteristics, while creating a serious problem for the market mechanism: the free-rider problem [3]. The free-rider problem is a primary factor that lead to market failures and prevent markets from achieving efficiency and equilibrium. Additionally, due to the special features of public goods, the supply of public goods determined by the market mechanism is much smaller than the Pareto optimal state. Since the market mechanism is failing in the provision of public goods, government intervention is necessary and inevitable to greatly alleviate such situation. As Mulder depicts in his study, for a consumer, because of the nonexclusive nature of public goods, once a public good is produced, every consumer can get the right to consume it without paying for it, and every consumer can get a ride [14].

A classical example of free-rider problem is that a crowded intersection is controlled by the absence of traffic lights and every car rushes through the intersection, thus causing the intersection to become more crowded and every car is unable to pass. The cost of setting up a traffic light is $\$ 50,000$, and the intersection passes 100,000 cars a year, and the cost saving per car is $\$ 10$ due to the passing of the intersection without any problems. Since the cost savings of $\$ 1,000,000$ is greater than $\$ 50,000$, it is efficient to set up the traffic light. However, a question emerges that the market is not likely to provide an efficient result. The non-exclusive nature of public goods makes the mechanism of obtaining the benefits of public goods through market exchange dysfunctional. For a traffic light provider, he or she must be able to exclude consumption from those who enjoy the traffic light without paying for it, otherwise he or she will not be able to cover the cost of production. For a consumer, on the other hand, because of the non-exclusivity of the public good, once the public good is produced, every consumer can get the right to consume it without paying for it, and every consumer can get a free ride.

Such behaviors of consumers imply that manufacturers who produce public goods may not receive benefits to cover the cost of production, and in the long run, manufacturers will not continue to provide such goods, which can make it difficult for public goods to be provided by the market, and such behaviors would largely harass the market order and lead to its failure [3]. Conversely, the market failure would aggravate the provision of public goods, as the failure may generate defects of the market mechanism in allocating resources reflected by the undersupply of public goods [11]. In essence, the production of public goods contradicts the role of the market mechanism; producers do not actively produce public goods. In contrast, public goods must be consumed by all members of society, and reflects the level of welfare of a country [13]. For this reason, the contradiction between the lag in the production of public goods and the needs of the members of society and economic development is greatly acute.

Attributed to the non-exclusive and non-competitive traits of public goods, the market is inefficient in their supply. Therefore, the supply of public goods is mainly provided by the government, but there are also private providers in the provision [11]. Government provision of public goods is not equivalent to that government produces all kinds of public goods. Those public goods solely produced and operated by the government often lack efficiency for a variety of reasons. Hence, the function of government should be providing public goods instead of producing them.

\section{The main ways in which public goods are provided and categories of government intervention.}

The first and foremost way is government provision that the government directly provides various public goods to citizens [17], which is the most common way in real life. Examples include national defense, security, public roads, water and sewerage, and etc..

The second and the popular adoption is the government contracts with private organizations [11]. The country or state contracts with businesses to operate public goods, which is the most adopted and widest form. The costs of public goods that fit this form are mainly natural monopolies with economies of scale, such as most of the infrastructures. If the country or state allows private enterprises to participate in the provision of 
public infrastructure and services on a build-operatetransfer (BOT) basis [18], that is the government allows private enterprises to invest in the construction of public infrastructure and operate it exclusively through a concession for a number of years, waiting until they recover. After recovering the investment and gaining profits, the government will then take over the public infrastructure, and the most commonly seen example is the high-speed road and expressway.

The third mode is that the government grants the private sector the right to operate. The government entrusts existing public infrastructures to private companies by granting operating rights, such as water companies and electricity supply [18]. In addition, there are many public services that are also operated in this way. The government grants those private companies the legal rights for urban sanitation management, green space maintenance, municipal facilities maintenance and etc. [12].

The fourth pattern is that the government subsidies private organizations to provide public goods, for instance, subsidized allowances, preferential loans, tax breaks, and etc.. The main areas where the government offers financial subsidies are science and technology, basic research, education, health care, housing, libraries and artistic realm [12].

Last but not least, private provision refers to private sectors directly provide various public goods to citizens, taking radio programs as an example [11]. Radio programs are public goods that are neither competitive nor exclusive. However, there are private offers, such as private radio stations, or privately-run programs that solely operated by private firms.

It is undoubted that private provision of public goods does not imply a complete separation from government or an abdication of government responsibility in this regard. Contrarily, government plays a crucial role in public management activities. Firstly, the major obstacle to private provision of public goods is the nonexclusivity of public goods, which makes charging for them impossible or fiscally uneconomical. Both the solution to the externality proposed by Coase's theorem and the joint supply and other supply methods we have discussed emphasize the link between property rights and efficiency. Therefore, in order to ensure efficient private provision of public goods, the government should clarify the property rights of public goods, so that the owner and the operator have the same goal, the mutual responsibility and benefit [15]. The political process will, in any case, shape private choices through its influence on key economic institutions. As a consequence, allocating property rights in a way that promotes efficiency and encourages the acceleration of the informatization process should be part of the government's responsibility [11]. To effectively hedge the supply risk of public goods and to give the suppliers an exact supply forecast, the government should also construct and stipulate the legal basis of the market system.

Just as there are some negative externalities associated with the government provision of public goods, due to the inherent flaws that can arise from marketization and privatization (for example, the existence of "trading points" leads to the corruption, and will result in the movement from government monopolies to private monopolies). Furthermore, there are also problems by private provision due to the characteristics of rational-economic man. For example, private ownership of a public good can lead to a monopoly advantage. By virtue of this monopoly advantage, the private party may raise the access price for the consumption of this public good, such as increasing the prices of highways, and etc.. There is also a possibility of deceiving consumers by not providing them with complete and transparent information [3]. In response to the above problems, it is the government's responsibility to provide necessary regulation and strengthen the institutional constraints on private organizations to effectively protect the rights and interests of the public.

In recent years, there is a burgeoning trend in discovering a new type of public goods provision, which is different from the traditional two routes to finance public goods: one path is to charge a fee, so that the people should pay to consume; the other path is to tax no matter people consume or not. The new route is voluntary contributions, as specifically, people do not always try to "free-ride". Many scholars have proposed a "voluntary provision model" [4], which suggests that it is possible for people to be willing to bear the cost of providing public goods without compulsory taxation or inevitable consumption. In China, a typical example of this is the voluntary blood donation and the recent rise of volunteerism.

Regarding the voluntary provision of public goods, it is not consistent with the assumption of economic man in economics, but the utility maximization could be either material or spiritual, and also tangible or intangible. They will have different degrees of influence on subjects with different preferences and constitute different incentives for different subjects. Among them, as Owen and Videras state that moral factors such as invisible ideology and virtues have particularly profound influence on subjects, which drive rational individuals to act in favor of others or other groups [16], and the provision of public goods in the form of voluntary donation is the result of such incentives.

Voluntary provision of public goods is commonly seen in reality, and it is in line with the moral principles of a civilized society, and should be promoted in all countries [16]. It is undeniable that voluntary provision is not unconditional, but within a good social atmosphere. Everyone lives in a group, and the behavior of others in the group has a decisive influence on his or her codes of conduct, that is, the social culture determines the behavior of individuals.

In this regard, a society in which many people freeride would end up in free-ride of everyone, and the result that the voluntary provision of public goods comes to nothing; whereas a society in which most people put in voluntary effort would end up with almost everyone is willing to actively provide their share of effort, and public goods can easily be produced under voluntary 
circumstances, which is the group effect of social provision of public goods. What' $\mathrm{s}$ more, it is critical to cultivate and promote social culture, and it often becomes the most important factor in society that affects the voluntary provision of public goods.

\section{Conclusion:}

As explained in this essay, the three issues are expounded explicitly and possible government actions are put forward to alleviate the situation. The dominating disparity that distinguish public goods from the others is whether these goods contain rivalry and exclusiveness. As for the second issue, being as a public organization, the government performs the function of directly providing certain public goods, as well as maintaining market order, eliminating externalities, regulating natural monopolies, information asymmetries, and so on, in order to compensate for market imperfections. However, it is difficult for the government to play both roles at the same time, but instead it leads to inefficient supply of public goods, resulting in market failures. Apart from the above reasons, the free-rider behavior of consumers also generates market failures. Consequently, it is inevitable to solve the problem by government intervention, but this is far from enough. Except for direct government provision, government contracts with private organizations, government' s grant, government subsidy and direct private provision, a new type of public goods provision, voluntary contributions becomes a buzz word, and would continuously thrive attributing to the fact that it deeply represents the culture and moral values of a country.

In view of this, this paper is not confined to the conceptual identification of public goods in the traditional sense, but to identify appropriate solutions by analyzing the market failures as well as government failures that occur when the government provides public goods. In fact, the choice of public goods supply method is based on one principle: the comparison of cost and benefit. Likewise, the government may intervene to moderate the status quo, but more importantly, as Anomaly claims that the government should take necessary information into consideration to form relevant government intervention, such as whether the costs of public provision exceed the benefits, and whether markets will, all things considered, produce a better or worse outcome than government action (2015). Even if government production is an important form of public goods supply, there is no denying that a large number of public goods are produced through the third sector, private organizations, and so on. Meanwhile, this paper also analyzes the latest mode of supply, voluntary contribution, which not only reflects the dynamic and relative nature of public goods, but also establishes a more diverse connection for the multi-channel supply of public goods that would offer new insights for further studies.

\section{References}

1. Book Review: "Joe Wallis and Brian Dollery, Market Failure, Government Failure, Leadership and Public Policy". London: Macmillan, 1999, p. 214.

2. Brian Dollery and Joseph Wallis. Market Failure, Government Failure, Leadership and Public Policy. Journal of Interdisciplinary Economics, 1997, April: 8 (2).

3. Byrne, Edmund F.. Public Goods and the Paying Public. Journal of Business Ethics. 1995: 14 (2), p. 117-123.

4. Chan, K.S., et al.. The Voluntary Provision of Public Goods under Varying Income Distributions. Canadian Journal of Economics, 1996, 29, p.54-69.

5. David M. Newbery. Road User Charges in Britain. The Economic Journal-Supplement: Conference Papers, 1988, Vol. 98, No. 390, p. 161-176.

6. David, N. King. The Political Economy of Local Government: Leadership, Reform and Market Failure. Economic Journal, August 15, 2008. https://doi.org/10.1111/1468-0297.t01-21-00083.

7. Brian Dollery and Joseph Wallis. WOLF'S MODEL: Government Failure and Public Sector Reform in Advanced Industrial Democracies. Review of Policy Research, 2002 March:19 (1), p.177-203.

8. Feigenbaum, Joseph Aaron. "Does the Substitution of Private Goods for Public Goods Result in Public Good?" Nova Southeastern University, Dissertations Publishing, 2003. 3096347.

9. Gao Hongye. "Fundamentals of Economics". Renmin University of China Press, 31 Zhongguancun Street, Beijing: October 2016, second edition.

10. Jennifer G., Mildred, et al. Privatization, Public Goods, and the Ironic Challenge of Free Trade Agreements. Administration \& Society, 2016.

11. Jonathan, Anomaly. Public Goods and Government Action. Politics Philosophy \& Economics, 2015, vol. 14(2), p. 109-128.

12. Manzoor, Sonia Hossain. "Effects of Government Policies on the Provision of Public Goods: A Theoretical and Empirical Investigation". Texas A\&M University, Dissertations Publishing, 1995. 9539262.

13. Meltzer, Allan H.. Market Failure or Government Failure?. Wall Street Journal, Eastern edition; New York, N.Y. 2010 (3): A.19.

14. Mulder, Arjen. Government Dilemmas in the Private Provision of Public Goods. Erasmus University Rotterdam, 2004. Retrieved from http://hdl.handle.net/1765/1790.

15. Ostrom V., Feeny D.. Rethinking institutional analysis and development: Issues, alternatives, and choices. 1993.

16. Owen A. L., Videras J. R.. Culture and public goods: The Case of Religion and the Voluntary Provision of Environmental Quality. Journal of Environmental Economics \& Management, 2007, 54(2), p.162-180.

17. Schmidtz, David. The Limits of Government : an Essay on the Public Goods Argument. American Political ence Review, 1991: 86. 2, p. 197-516.

18. Villanacci, Antonio and Zenginobuz, Ünal. Pareto Improving Interventions in a General Equilibrium 
Model with Private Provision of Public Goods. Review of Economic Design, 2006: 10, p. 249-271.

19. Zerbe, Richard O, Jr; McCurdy, Howard E. The Failure of Market Failure. Journal of Policy Analysis and Management, 1999: 18 (4), p. 558-578. 